\title{
Investigations towards the stereoselective organocatalyzed Michael addition of dimethyl malonate to a racemic nitroalkene: possible route to the 4-methyl- pregabalin core structure
}

\author{
Denisa Vargová, Rastislav Baran and Radovan Šebesta*
}

\author{
Full Research Paper \\ Address: \\ Department of Organic Chemistry, Faculty of Natural Sciences, \\ Comenius University in Bratislava, Mlynská dolina, Ilkovičova 6, \\ SK-842 15 Bratislava, Slovakia \\ Email: \\ Radovan Šebesta* - radovan.sebesta@uniba.sk \\ * Corresponding author \\ Keywords: \\ kinetic resolution; Michael addition; organocatalysis; pregabalin; \\ squaramide
}

Beilstein J. Org. Chem. 2018, 14, 553-559. doi:10.3762/bjoc.14.42

Received: 31 July 2017

Accepted: 18 February 2018

Published: 05 March 2018

Associate Editor: M. Rueping

(c) 2018 Vargová et al.; licensee Beilstein-Institut.

License and terms: see end of document.

\begin{abstract}
Chiral derivatives of $\gamma$-aminobutyric acid are widely used as medicines and can be obtained by organocatalytic Michael additions. We show here the stereoselective synthesis of 4-methylpregabalin stereoisomers using a Michael addition of dimethyl malonate to a racemic nitroalkene. The key step of the synthesis operates as a kinetic resolution with a chiral squaramide catalyst. Furthermore, specific organocatalysts can provide respective stereoisomers of the key Michael adduct in up to 99:1 er.
\end{abstract}

\section{Introduction}

Asymmetric organocatalysis has considerably broadened possibilities for stereoselective synthesis of bioactive compounds [1-3]. In particular, stereoselective conversions of nitro compounds served in many syntheses of pharmaceuticals [4].

Derivatives of $\gamma$-aminobutyric acid are an important class of medicines targeting problems with the central nervous system, such as pains, seizures, or epilepsy. Several mono- and dialkyl substituted derivatives, known as gabapentinoids, are currently used in clinical praxis. Important members of this class such as phenibut, gabapentin, or pregabalin have anticonvulsant, anxiolytic, and analgesic mode of actions [5]. Pregabalin (Figure 1) is one of the most widely used medicines for the treatment of neuropathic pains and partial seizures. It is also known that the $(S)$-enantiomer is approximately 10 times more active than the $(R)$-enantiomer. Medicinal properties of alkyl derivatives of pregabalin were also investigated. Wustrow and co-workers showed that the presence of another stereogenic center in the molecule and its configuration have a dramatic effect on the activity of these compounds [6]. This study also showed that 
4-methylpregabalin (1, Figure 1) has higher activities than pregabalin (Figure 1). Methylpregabalin and related amino acids have also been investigated as treatments for ocular disorders [7]. However, the syntheses of this type of compounds were long and relied on the use of Evans chiral auxiliaries or chiral starting materials.<smiles>CC(C)CC(CN)CC(=O)O</smiles>

pregabalin<smiles>CC(C)C(C)C(CN)CC(=O)O</smiles>

4-methylpregabalin (1)
Figure 1: Structures of pregabalin and methylpregabalin.

Various GABA derivatives were synthesized using asymmetric organocatalysis. Stereoselective Michael addition, one of the most important organocatalytic reactions [8] usually serves as a key stereoinduction transformation. Earlier studies, performed by Hayashi and Wang employed iminium activation to perform the enantioselective addition of nitromethane to enals for syntheses of baclofen and pregabalin $[9,10]$. Later, hydrogen-bonding activation proved to be more general for obtaining Michael adducts via the addition of 1,3-dicarbonyl compounds to nitroalkenes. Chiral thioureas and squaramides, particularly those with the bifunctional mode of action, served as excellent catalysts in numerous Michael additions, as well as other reactions [11-14]. In this way, chiral thioureas, and squaramides were used to synthesize various GABA derivatives [15-19]. Interestingly, hydrogen-bonding activation of this kind of Michael additions worked well also in aqueous media [20,21]. Other green chemistry concepts such as reusable media [22], immobilized catalysts [23], or flow set-ups have also been used with success for the synthesis of GABA derivatives [24].

Pregabalin is currently manufactured using enzymatic kinetic resolution [25], but an organocatalytic procedure based on chiral phase-transfer-catalysis of the Michael addition was also reported [26].
In this context, we decided to develop a synthesis of 4-methylpregabalin from a simple and achiral starting material and build its chirality centers using asymmetric catalysis. This paper describes the synthesis of 4-methylpregabalin from ethyl 3-methylbutanoate using an organocatalytic Michael addition as the stereoinduction step.

\section{Results and Discussion}

The starting material for the Michael addition was synthesized from ethyl 3-methylbutanoate (2). This straightforward sequence comprised methylation, reduction, nitro-aldol reaction, and dehydration (Scheme 1). Methylation of the ester $\mathbf{2}$ in the alpha position proceeded easily with LDA as a base and methyl iodide as an alkylating agent. The ester functionality was then reduced with DIBAL in dichloromethane to afford aldehyde 4 in $90 \%$ yield. A base-mediated addition of nitromethane to the aldehyde $\mathbf{4}$ provided nitro alcohol $\mathbf{5}$. The somewhat lower yield $(58 \%)$ of the aldol product 5 is likely caused by the reversibility of the nitro-aldol reaction. The yield of this reaction did not improve with longer time and unreacted aldehyde was still present in the reaction mixture. Nitroaldol product 5 was then dehydrated using the $\mathrm{CuCl} / \mathrm{DCC}$ protocol [16] to nitroalkene 6. Overall, this sequence afforded the desired racemic Michael acceptor $\mathbf{6}$ in total $36 \%$ yield over four steps.

With Michael acceptor 6 in hands, we started to investigate the 1,4-addition of dimethyl malonate catalyzed by hydrogen-bonddonating organocatalysts (Scheme 2). We have also briefly investigated Meldrum's acid as a donor, instead of dimethyl malonate, but we have obtained a complicated reaction mixture, which was difficult to purify. Therefore, we have focused our attention on the Michael addition of dimethyl malonate. An initial catalyst screening was performed in dichloromethane, based on our previous experiences with this type of Michael additions [18]. We have employed a range of squaramide and thiourea organocatalysts C1-C7 [18,27-34], as well as two newly synthesized binaphthol-squaramide catalysts $\left(S_{a}, R, R\right)$ C8, and $\left(S_{a}, S, S\right)$-C8 (Scheme 3). Results of the initial catalyst screening are summarized in Table 1.

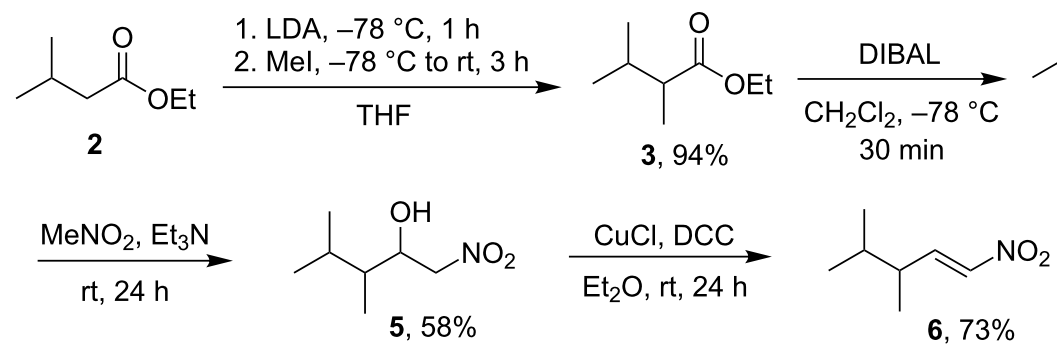




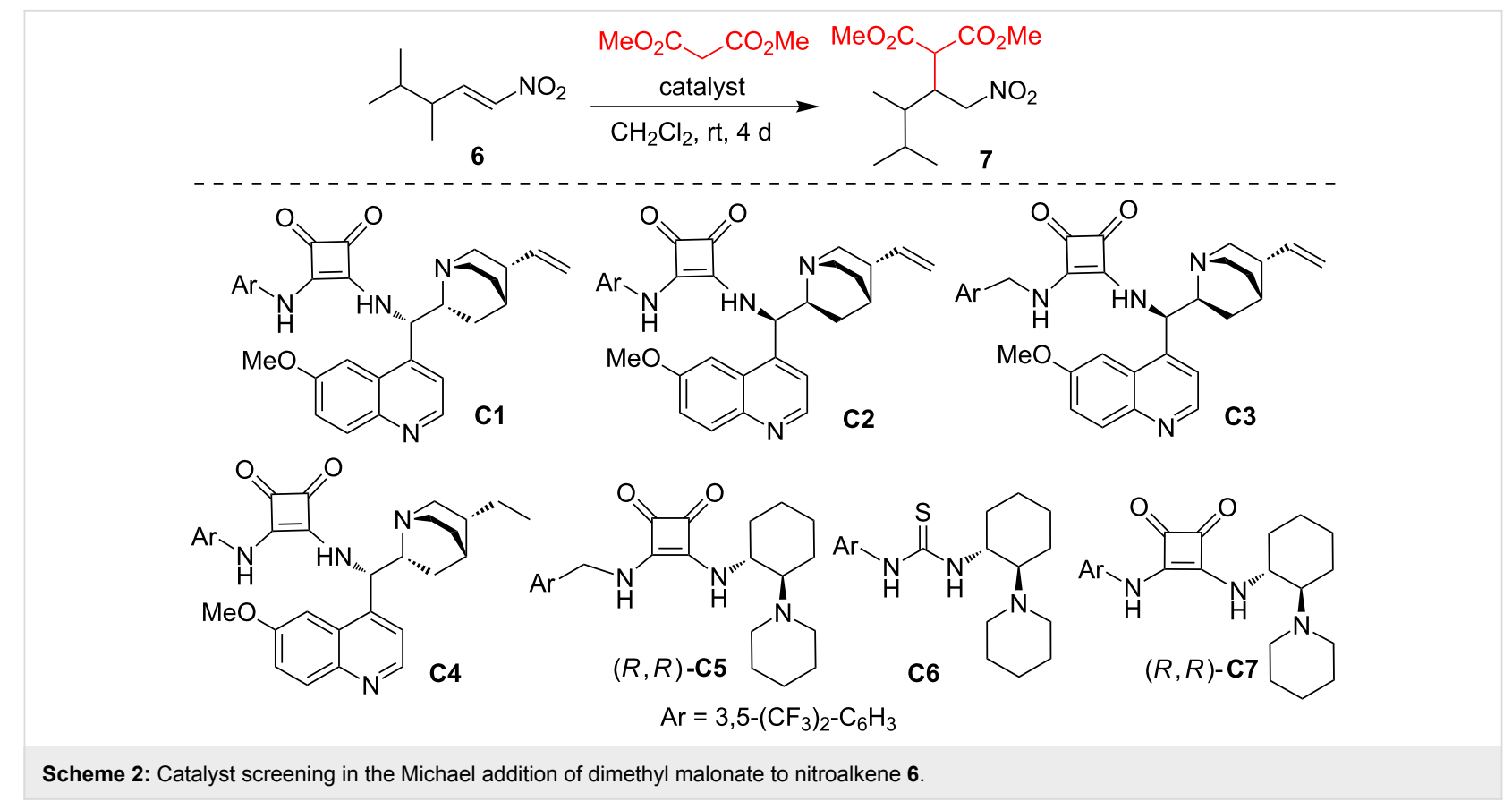<smiles>COc1ccc2ccccc2c1-c1c(OC)c(CN)c2ccccc2c1N=[W]</smiles>

9, $70 \%$

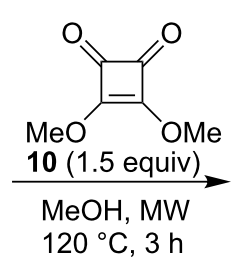

$120^{\circ} \mathrm{C}, 3 \mathrm{~h}$<smiles>COc1c(NCc2cc3ccccc3c(-c3c(O)ccc4ccccc34)c2O)c(=O)c1=O</smiles>

$11,80 \%$

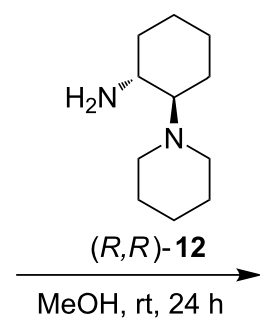

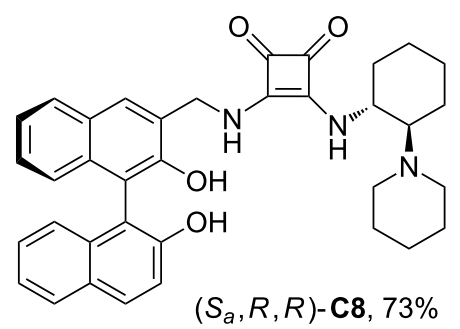

$\left(S_{a}, S, S\right)-\mathbf{C 8}, 68 \%$ using $(S, S)-12$

Scheme 3: Synthesis of catalysts $\left(S_{a}, R, R\right)-\mathbf{C 8}$ and $\left(S_{a}, S, S\right)$-C8.

The binaphthyl structural motif has already been employed in the hydrogen-bond-donating organocatalysis $[35,36]$. However, the binaphthol moiety possessing an additional hydrogen bond donor group was not tested in too much depth. Therefore, we have synthesized two binaphthol-based diastereomeric squaramide catalysts $\left(S_{a}, R, R\right)$ - $\mathbf{C 8}$ and $\left(S_{a}, S, S\right)$-C8 (Scheme 3$)$. Starting from $(S)$-BINOL $(8)$, amine 9 was obtained in five steps following literature procedures (see Supporting Informa- tion File 1 for more details) [37-40]. The amine 9 was then attached to a squaramide moiety using dimethyl squarate (10) in slight excess to ensure monosubstitution. In this way compound 11 was isolated in $80 \%$ yield. We have originally envisaged the transformation from amine $\mathbf{9}$ to compound $\mathbf{1 1}$ in two steps. However, under microwave heating conditions, both couplings of the amino group with squarate, as well as methoxymethyl (MOM) deprotection was observed. To the best 


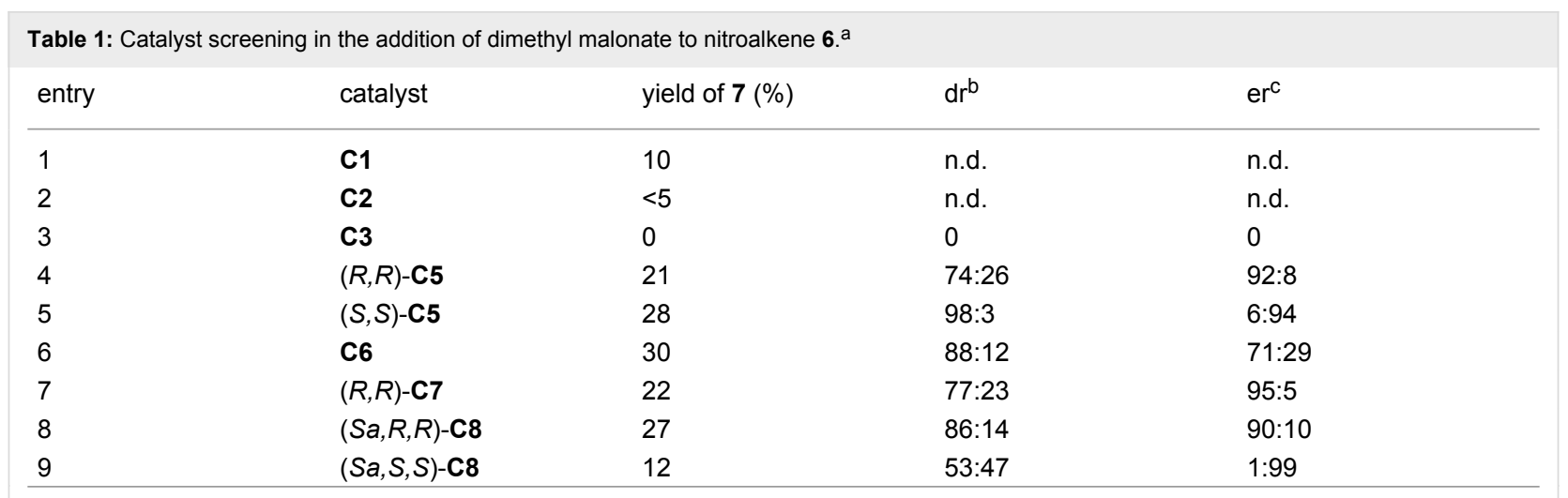

${ }^{a}$ General conditions: nitroalkene $6(1.4 \mathrm{mmol})$, dimethyl malonate $(1.4 \mathrm{mmol})$, catalyst $(0.07 \mathrm{mmol}, 5 \mathrm{~mol} \%)$ in $\mathrm{CH}_{2} \mathrm{Cl}_{2}(1.5 \mathrm{~mL})$ was stirred at rt

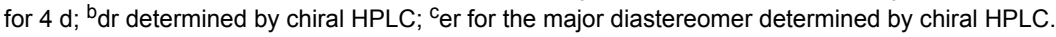

of our knowledge, there is no report describing methanolysis of MOM-groups under microwave conditions. This transformation is perhaps similar to acetal hydrolysis in neat water under microwave irradiation [41]. Because of this efficient process, compound 11 was isolated in one synthetic operation in $80 \%$ yield from amine 9 . In the last step, precursor 11 reacted with either amine $(R, R)-\mathbf{1 2}$ or $(S, S) \mathbf{- 1 2}$, to afford diastereoisomeric catalysts $\left(S_{a}, R, R\right)-\mathbf{C 8}$, and $\left(S_{a}, S, S\right)$-C8, respectively.

In the Michael addition of dimethyl malonate to the racemic nitroalkene 6, the cinchona-based catalysts $\mathbf{C 1}-\mathbf{C 3}$ performed poorly and provided the desired Michael adduct 7 in less than $10 \%$ yields (Table 1 , entries $1-3$ ). The lower reactivity of the nitroalkene $\mathbf{6}$ compared with that of similar Michael acceptors is probably due to the higher steric hindrance near the $\beta$-carbon caused by branching of the alkyl chain. More relevant results in the Michael addition were obtained with more reactive, and likely less hindered, catalysts C5-C8, which afforded adduct 7 in up to $30 \%$ yield (Table 1, entries 4-9).

As the results of the Michael addition in dichloromethane were not fully satisfactory with neither of the nine tested catalysts, we have decided to test the reaction in other solvents. Using catalyst $(S, S)$-C5, we have evaluated the Michael addition of dimethyl malonate to nitroalkene $\mathbf{6}$ in several other solvents (Table 2). The best results were obtained in toluene. We have observed a dramatic increase of the yield of compound 7. Its enantiomeric purity was also the highest (er 99:1) in toluene. Similarly, high enantiomeric purities were also observed in acetonitrile and methanol, but yields were lower in these solvents. This transformation likely operates as a kinetic resolution that creates a further stereocenter. We have also recovered unreacted nitroalkene $\mathbf{6}$ with enantiomeric purity of approx. 67:33 er. Given the recent successful Michael additions to nitroalkenes in aqueous media [20,21], we have also tested the Michael addition of dimethyl malonate to nitroalkene 6 in brine. For this experiment, we have employed the more lipophilic organocatalyst $\mathbf{C 4}$, but the desired adduct 7 was formed only in small amount ( $14 \%$ determined by NMR).

Using quantum chemical calculations, we propose approximate transition state models for the stereoselective Michael addition (Figure 2). Geometrical optimizations were performed at HF/6$31 \mathrm{G}^{*}$ level and energies were further refined using M06-2X functional with $6-311+\mathrm{G}^{* *}$ basis set. Solvation effects were evaluated by using conductor-like C-PCM model with toluene

\begin{tabular}{|c|c|c|c|c|}
\hline solvent & catalyst & yield (\%) & $d r^{b}$ & $e r^{c}$ \\
\hline $\mathrm{CH}_{2} \mathrm{Cl}_{2}$ & $(S, S)-\mathbf{C 5}$ & 28 & $98: 2$ & $94: 6$ \\
\hline toluene & $(S, S)-\mathbf{C 5}$ & 75 & $68: 32$ & $>99: 1$ \\
\hline toluene & $\left(S_{a}, S, S\right)-\mathbf{C 8}$ & 36 & $62: 38$ & $84: 15$ \\
\hline $\mathrm{MeCN}$ & $(S, S)-\mathbf{C 5}$ & 29 & $71: 29$ & $>99: 1$ \\
\hline Me-THF & $(S, S)-\mathbf{C 5}$ & 31 & $76: 24$ & $97: 3$ \\
\hline $\mathrm{MeOH}$ & $(S, S)-\mathbf{C 5}$ & 37 & $73: 27$ & $>99: 1$ \\
\hline brine $e^{d}$ & $\mathrm{C} 4$ & 14 & n.d. & n.d. \\
\hline
\end{tabular}

aGeneral conditions: nitroalkene $6(1.4 \mathrm{mmol})$, dimethyl malonate $(1.4 \mathrm{mmol})$, catalyst $(0.07 \mathrm{mmol}, 5 \mathrm{~mol} \%)$ in solvent $(1.5 \mathrm{~mL})$ was stirred at $\mathrm{rt}$ for $4 \mathrm{~d}$; ${ }^{b} \mathrm{dr}$ determined by chiral HPLC; ${ }^{c}$ er for the major diastereomer determined by chiral HPLC; ${ }^{d}$ reaction time $48 \mathrm{~h}$. 

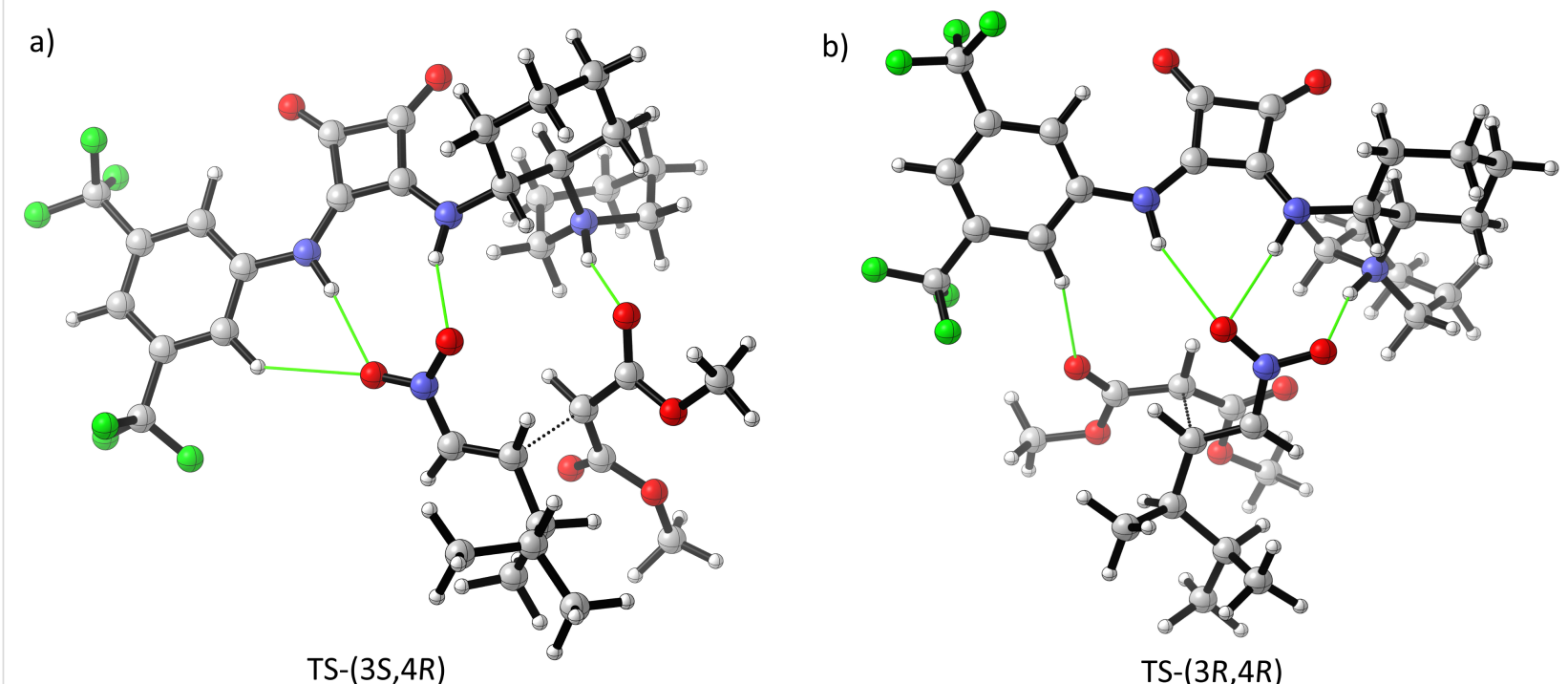

Figure 2: Transition state models for the reaction of $(R)-6$ with dimethyl malonate using catalyst $\mathrm{C} 7(\mathrm{M} 06-2 \mathrm{X} / 6-311+\mathrm{G}$ **-C-PCM(toluene)//HF/6$\left.31 \mathrm{G}^{*}\right)$.

as solvent (see Supporting Information File 1 for more details). The model envisages dual activation mode originally suggested by Takemoto [42], and then applied in similar situations $[18,43,44]$. In this model, the nitroalkene is bound to the catalyst via a squaramide moiety including an ancillary $\mathrm{C}-\mathrm{H} \cdots \mathrm{O}$ hydrogen bond $[45,46]$. The dimethyl malonate anion binds via the protonated tertiary amide group. The calculations suggest that using organocatalyst $\mathbf{C} 7$ the preferred enantiomers of the product, within like and unlike-diastereomers, have $(3 R, 4 R)$ and $(3 S, 4 R)$-configuration. These isomers would result from the $R e$-face and $S i$-attack of dimethyl malonate anion to $(R)$-enantiomer of the nitroalkene $\mathbf{6}$.

Enantiomerically enriched Michael adduct 7, which was obtained with catalyst $(S, S)$-C5, was also used to finish the synthe- sis of 4-methylpregabalin (1) in an analogy to literature procedures (Scheme 4) [47]. Adduct 7 was transformed to lactone 13 via nitro group reduction with $\mathrm{NaBH}_{4} / \mathrm{NiCl}_{2}$ followed by spontaneous lactamization. In the last step, lactam 13 was hydrolyzed and decarboxylated to give 4-methylpregabalin hydrochloride $(\mathbf{1} \cdot \mathrm{HCl})$. We have measured specific optical rotation for compound 1 to be $[\alpha]_{\mathrm{D}}{ }^{20}-2.6(c 0.95, \mathrm{MeOH})$. This value corresponds better with literature data, which for the $(3 R, 4 R)$ isomer states $[\alpha]_{\mathrm{D}}{ }^{20}-5.3$ whereas for $(3 R, 4 S)[\alpha]_{\mathrm{D}}{ }^{20}+14.9$.

\section{Conclusion}

We have shown that 4-methylpregabalin stereoisomers can be synthesized from ethyl 3-methylbutanoate. The key step is an organocatalytic Michael addition of dimethyl malonate to racemic nitroalkene 6. Using chiral squaramide organocatalyst,

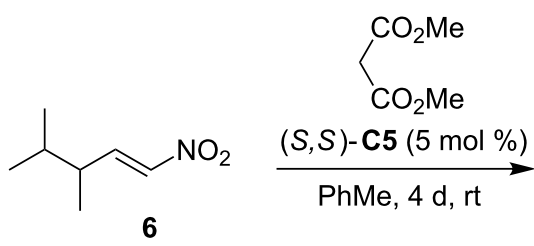

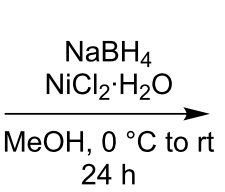<smiles>COC(=O)[C@H]1C(=O)NC[C@@H]1[C@H](C)C(C)O</smiles>

$13,50 \%$<smiles>COC(=O)C(C(C)OC)C(C[N+](=O)[O-])C(C)C(C)OC</smiles>

7, $75 \%$, dr 68:32, er $>99: 1$

1. $\mathrm{HCl}, 50 \%$ 
the desired Michael adduct 7 was obtained in $75 \%$ yield as a mixture of diastereomers (dr 68:32) with very high enantiomeric purity of the major diastereomer (er 99:1). With the help of quantum-chemical calculations, we have proposed a transition state model for the Michael addition.

\section{Supporting Information}

\section{Supporting Information File 1}

Experimental procedures, characterization data for all compounds, pictures of NMR spectra and computational details.

[https://www.beilstein-journals.org/bjoc/content/ supplementary/1860-5397-14-42-S1.pdf]

\section{Acknowledgements}

This publication is the result of the project implementation: 26240120025 supported by the R\&DOP funded by the European Regional Development Fund.

\section{ORCID ${ }^{\circledR}$ iDs}

Radovan Šebesta - https://orcid.org/0000-0002-7975-3608

\section{References}

1. Vetica, F.; Chauhan, P.; Dochain, S.; Enders, D. Chem. Soc. Rev. 2017, 46, 1661-1674. doi:10.1039/C6CS00757K

2. Alemán, J.; Cabrera, S. Chem. Soc. Rev. 2013, 42, 774-793. doi:10.1039/C2CS35380F

3. Marcia de Figueiredo, R.; Christmann, M. Eur. J. Org. Chem. 2007, 2575-2600. doi:10.1002/ejoc.200700032

4. Sukhorukov, A. Y.; Sukhanova, A. A.; Zlotin, S. G. Tetrahedron 2016, 72, 6191-6281. doi:10.1016/j.tet.2016.07.067

5. Corey, E. J.; Czakó, B.; Kürti, L. Molecules and Medicine; Wiley: Hoboken, 2007.

6. Belliotti, T. R.; Capiris, T.; Ekhato, I. V.; Kinsora, J. J.; Field, M. J.; Heffner, T. G.; Meltzer, L. T.; Schwarz, J. B.; Taylor, C. P.;

Thorpe, A. J.; Vartanian, M. G.; Wise, L. D.; Zhi-Su, T.; Weber, M. L.; Wustrow, D. J. J. Med. Chem. 2005, 48, 2294-2307. doi:10.1021/jm049762।

7. Palczewski, K.; Maeda, A.; Golczak, M.; Case Western Reserve University USA. WO Patent 2011071995, 2011; pp $111 \mathrm{ff}$.

8. Tsogoeva, S. B. Eur. J. Org. Chem. 2007, 1701-1716. doi:10.1002/ejoc.200600653

9. Gotoh, H.; Ishikawa, H.; Hayashi, Y. Org. Lett. 2007, 9, 5307-5309. doi:10.1021/ol702545z

10. Zu, L.; Xie, H.; Li, H.; Wang, J.; Wang, W. Adv. Synth. Catal. 2007, 349, 2660-2664. doi:10.1002/adsc.200700353

11. Siau, W.-Y.; Wang, J. Catal. Sci. Technol. 2011, 1, 1298-1310. doi:10.1039/c1cy00271f

12. Serdyuk, O. V.; Heckel, C. M.; Tsogoeva, S. B. Org. Biomol. Chem. 2013, 11, 7051-7071. doi:10.1039/c3ob41403e

13. Chauhan, P.; Mahajan, S.; Kaya, U.; Hack, D.; Enders, D. Adv. Synth. Catal. 2015, 357, 253-281. doi:10.1002/adsc.201401003
14. Held, F. E.; Tsogoeva, S. B. Catal. Sci. Technol. 2016, 6, 645-667. doi:10.1039/C5CY01894C

15. Bassas, O.; Huuskonen, J.; Rissanen, K.; Koskinen, A. M. P. Eur. J. Org. Chem. 2009, 1340-1351. doi:10.1002/ejoc.200801220

16. Liu, J.-m.; Wang, X.; Ge, Z.-m.; Sun, Q.; Cheng, T.-m.; Li, R.-t. Tetrahedron 2011, 67, 636-640. doi:10.1016/j.tet.2010.11.053

17. Kimmel, K. L.; Weaver, J. D.; Ellman, J. A. Chem. Sci. 2012, 3, 121-125. doi:10.1039/C1SC00441G

18. Baran, R.; Veverková, E.; Škvorcová, A.; Šebesta, R. Org. Biomol. Chem. 2013, 11, 7705-7711. doi:10.1039/c3ob41709c

19. Veverková, E.; Bilka, S.; Baran, R.; Šebesta, R. Synthesis 2016, 48, 1474-1482. doi:10.1055/s-0035-1560420

20. Bae, H. Y.; Song, C. E. ACS Catal. 2015, 5, 3613-3619. doi:10.1021/acscatal.5b00685

21. Sim, J. H.; Song, C. E. Angew. Chem., Int. Ed. 2017, 56, 1835-1839. doi:10.1002/anie.201611466

22. Feu, K. S.; de la Torre, A. F.; Silva, S.; de Moraes Junior, M. A. F.; Corrêa, A. G.; Paixão, M. W. Green Chem. 2014, 16, 3169-3174. doi:10.1039/C4GC00098F

23. Tukhvatshin, R. S.; Kucherenko, A. S.; Nelyubina, Y. V.; Zlotin, S. G. ACS Catal. 2017, 7, 2981-2989. doi:10.1021/acscatal.7b00562

24. Porta, R.; Benaglia, M.; Coccia, F.; Rossi, S.; Puglisi, A. Symmetry 2015, 7, 1395-1409. doi:10.3390/sym7031395

25. Martinez, C. A.; Hu, S.; Dumond, Y.; Tao, J.; Kelleher, P.; Tully, L. Org. Process Res. Dev. 2008, 12, 392-398. doi:10.1021/op7002248

26. Moccia, M.; Cortigiani, M.; Monasterolo, C.; Torri, F.; Del Fiandra, C.; Fuller, G.; Kelly, B.; Adamo, M. F. A. Org. Process Res. Dev. 2015, 19, 1274-1281. doi:10.1021/acs.oprd.5b00160

27. Dai, L.; Wang, S.-X.; Chen, F.-E. Adv. Synth. Catal. 2010, 352, 2137-2141. doi:10.1002/adsc.201000334

28. Yang, W.; Du, D.-M. Org. Lett. 2010, 12, 5450-5453. doi:10.1021/ol102294g

29. Jiang, H.; Paixão, M. W.; Monge, D.; Jørgensen, K. A. J. Am. Chem. Soc. 2010, 132, 2775-2783. doi:10.1021/ja9097803

30. Bae, H. Y.; Some, S.; Lee, J. H.; Kim, J.-Y.; Song, M. J.; Lee, S.; Zhang, Y. J.; Song, C. E. Adv. Synth. Catal. 2011, 353, 3196-3202. doi:10.1002/adsc. 201100458

31. George, J.; Sridhar, B.; Reddy, B. V. S. Org. Biomol. Chem. 2014, 12, 1595-1602. doi:10.1039/c3ob42026d

32. Konishi, H.; Lam, T. Y.; Malerich, J. P.; Rawal, V. H. Org. Lett. 2010, 12, 2028-2031. doi:10.1021/ol1005104

33. Qian, Y.; Ma, G.; Lv, A.; Zhu, H.-L.; Zhao, J.; Rawal, V. H. Chem. Commun. 2010, 46, 3004-3006. doi:10.1039/b922120d

34. Jing, Z.; Bai, X.; Chen, W.; Zhang, G.; Zhu, B.; Jiang, Z. Org. Lett. 2016, 18, 260-263. doi:10.1021/acs.orglett.5b03412

35. Wang, J.; Li, H.; Duan, W.; Zu, L.; Wang, W. Org. Lett. 2005, 7, 4713-4716. doi:10.1021/ol0519137

36. Alegre-Requena, J. V.; Marqués-López, E.; Herrera, R. P. Adv. Synth. Catal. 2016, 358, 1801-1809. doi:10.1002/adsc. 201600046

37. Beckendorf, S.; Mancheño, O. G. Synthesis 2012, 44, 2162-2172. doi:10.1055/s-0031-1291009

38. Hodačová, J.; Stibor, I. Collect. Czech. Chem. Commun. 2000, 65, 83-98. doi:10.1135/cccc20000083

39. Zhang, A.-L.; Yu, Z.-d.; Yang, L.-W.; Yang, N.-F. Tetrahedron: Asymmetry 2015, 26, 173-179. doi:10.1016/j.tetasy.2014.12.012

40. Probst, N.; Madarász, Á.; Valkonen, A.; Pápai, I.; Rissanen, K.; Neuvonen, A.; Pinko, P. M. Angew. Chem., Int. Ed. 2012, 51, 8495-8499. doi:10.1002/anie.201203852 
41. Polshettiwar, V.; Varma, R. S. Chem. Soc. Rev. 2008, 37, 1546-1557. doi:10.1039/b716534j

42. Okino, T.; Hoashi, Y.; Furukawa, T.; Xu, X.; Takemoto, Y. J. Am. Chem. Soc. 2005, 127, 119-125. doi:10.1021/ja044370p

43. Noole, A.; Järving, I.; Werner, F.; Lopp, M.; Malkov, A.; Kanger, T. Org. Lett. 2012, 14, 4922-4925. doi:10.1021/ol302245b

44. Etxabe, J.; Izquierdo, J.; Landa, A.; Oiarbide, M.; Palomo, C. Angew. Chem., Int. Ed. 2015, 54, 6883-6886. doi:10.1002/anie.201501275

45. Nagorny, P.; Sun, Z. Beilstein J. Org. Chem. 2016, 12, 2834-2848. doi:10.3762/bjoc. 12.283

46. Johnston, R. C.; Cheong, P. H.-Y. Org. Biomol. Chem. 2013, 11, 5057-5064. doi:10.1039/c3ob40828k

47. Sukhanova, A. A.; Nelyubina, Y. V.; Zlotin, S. G. Mendeleev Commun. 2016, 26, 471-473. doi:10.1016/j.mencom.2016.11.003

\section{License and Terms}

This is an Open Access article under the terms of the Creative Commons Attribution License

(http://creativecommons.org/licenses/by/4.0), which permits unrestricted use, distribution, and reproduction in any medium, provided the original work is properly cited.

The license is subject to the Beilstein Journal of Organic Chemistry terms and conditions:

(https://www.beilstein-journals.org/bjoc)

The definitive version of this article is the electronic one which can be found at: doi: $10.3762 /$ bjoc. 14.42 